Please send trade news information and

illustrations to Arveen Bajaj at the $B D J$, Nature

Publishing Group, The Macmillan Building,

4-6 Crinan Street, London N1 9XW.

Trade news is provided as a service to readers

using text and images from the manufacturer,

supplier or distributor and does not imply

endorsement by the $B D J$. Normal and prudent

research should be exercised before purchase or

use of any product mentioned.

\section{Tooth grinding solution}

Patients with bruxism problems may benefit from newly introduced Dr Brux. It is a simple and economical solution that is easy to use, totally eliminating the problem associated with bruxism on the very first night the Dr Brux trays are worn.

The Dr Brux tray is moulded to the exact shape of the patients' mouth, making it very comfortable to wear. To alleviate bruxism your patient simply pops the tray into his/her mouth at night and removes it in the morning. Your patients will wake up feeling relaxed and refreshed.

Bruxism often remains undiagnosed and can result in a multitude of problems ranging from tooth wear, muscular ten-

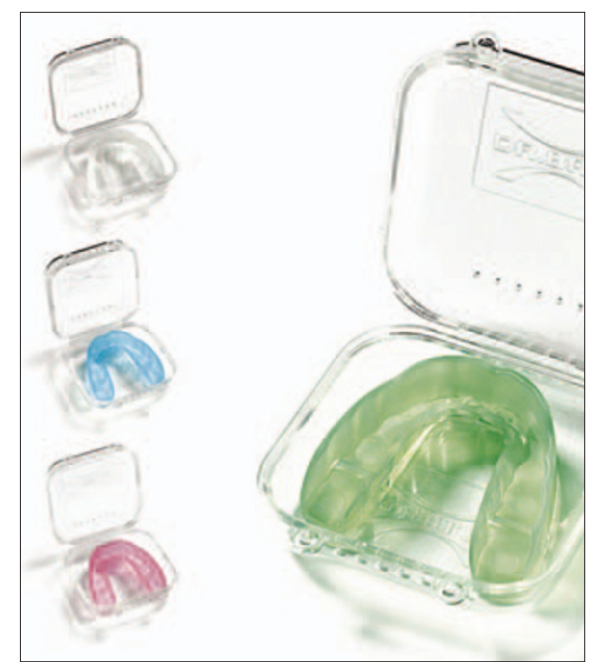

sion and sleep disturbance. Tooth sensitivity, migraine and general fatigue are also often also associated with bruxism. Reader response number 50

\section{Text reminders for forgetful patients}

DNAs are a problem common to most practices and in many cases the appointment has simply been forgotten. Charging for missed appointments can help reduce the incidence; however, this often generates bad feeling and can result in the patient taking their custom elsewhere.

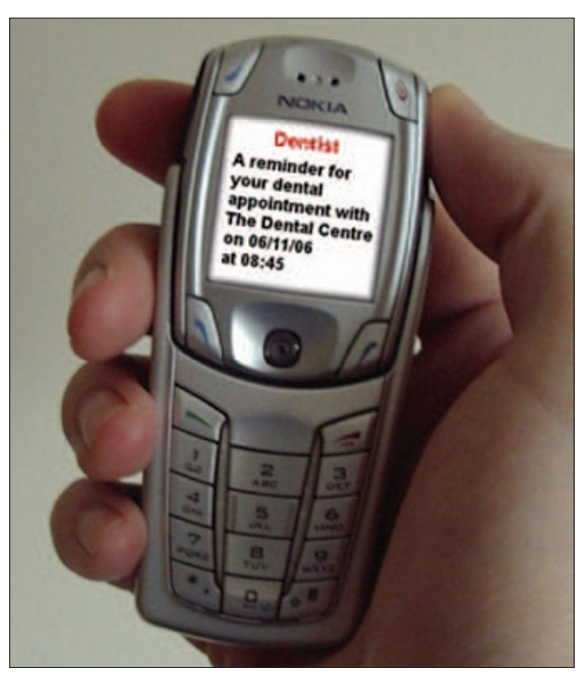

With the majority of the population owning a mobile phone it makes sense to use a text message to remind patients of their impending appointment. SMS Plus from Software of Excellence allows you to do just that. They will work out how many appointments you are likely to make over a defined period and calculate the amount of text messages you will require.

Should your business increase, you will never be left short, as they will monitor your usage and notify you in the event that you need to purchase more and will carry over any that you have left at the end of each month.

Various reports can be generated to advise how many texts went through etc. The practice can also text land lines and can set the messages to run at whatever intervals they like so there really is no excuse for missed appointments.

Patients also find a text message less intrusive than a phone call and it can act as a diary entry and constant reminder to attend the appointment. Text messaging is quick, easy and cost effective - the rate per text is very competitive.

Reader response number 52

\section{Easy to understand patient information}

Straumann's website makes it possible for visitors to take full advantage of a wide range of services using innovative internet communications.

The site has an easy to use product finder feature on each local country site making it easier for dental professionals to access all the products available within their country either by name or indication.

The regularly updated corporate page features corporate content, financial analysis, investor and media information whilst a newly designed patient section provides easy to understand patient information and brochures which can be downloaded for individual use.

Focusing largely on accessibility, the structure of the website has been designed to make navigation easier for visitors enabling them to find their desired information with ease. Visit it at www.straumannuk.com.

Reader response number 51

\section{Stylish and hard-wearing}

Tavom's Classic C3000 range of cabinetry and surgery suites offers the ultimate in choice to create a practical and aesthetically pleasing working environment.

The C3000 portfolio includes a wide and versatile selection of sink units, mobile modular units, cabinets and storage facilities.

All are designed and manufactured to Tavom's standards and enable clinicians to create their own, individual work spaces to complement their own specific tastes and needs.

The range includes modern, innovative designs with attention to detail making them attractive, durable and hard wearing.

Reader response number 53 

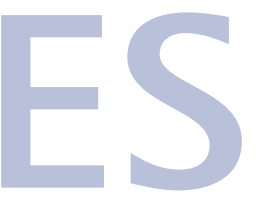

\section{Highly filled nano-hybrid}

Miris 2 is a development and improvement based on existing Miris technology. A radio-opaque, highly filled nano-hybrid composite, it provides restorations that meet with harmony of light, material and colour. The product, from Coltene Whaledent has a natural layering concept, which differentiates between younger, adult and older patients.

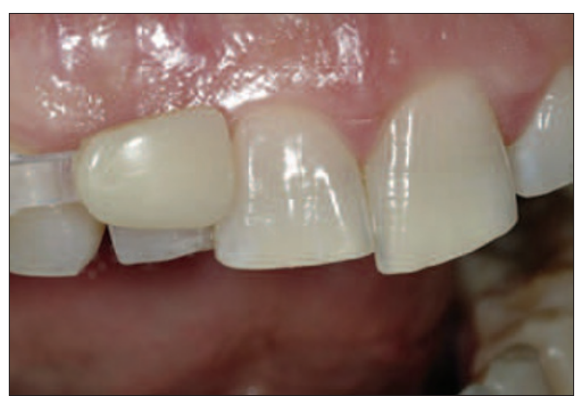

It is combined with a new adjusted unique shade guide that shows a combination of enamel and dentin layer and allows an accurate preview of the finished restoration and perfect natural mimicry, brightness and vitality.

With optimised handling properties and reduced shrinkage Miris 2 has been kept as simple as possible to use whilst still providing distinctive characteristic colours and opalescence.

Reader response number 54

\section{Unique delivery system}

Dentsply's flowable composite, X-Flow is a universal partner for diverse light cure materials and can therefore be used as a liner with any composite, compomer or ormocer.

X-Flow combines physical properties with a unique delivery system called compula.

The compula offers convenience with accurate placement and the long, thin metal tip provides the precision needed for direct application of X-Flow to deep and hard-to-reach cavities.

This flexibility is invaluable when a flowable composite is required to repair existing restorations. From $1^{\text {st }}$ May until $30^{\text {th }}$ July 2007, each time you order a CombiPack of IRM Powder-Liquid through your preferred dealer, you will receive a free mini-sample of $\mathrm{X}$ Flow that you can try in your practice. Reader response number 55

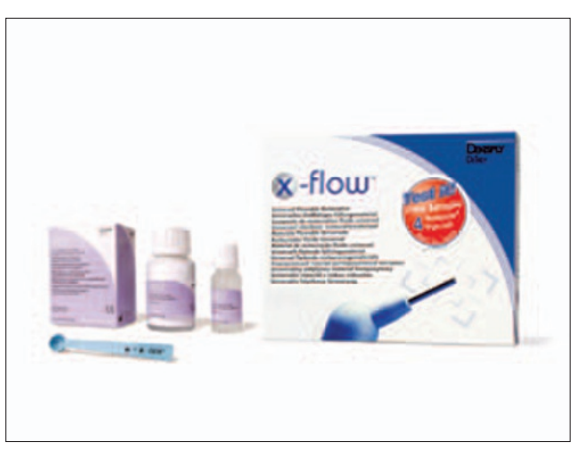

gam is provided with the option of three interchangeable nozzles (straight, $45^{\circ}$ and $90^{\circ}$ ) which can also be purchased separately.

Astek have developed the Pegasus Amalgam Well to compliment their range of Amalgam Carriers. Each well is machined from a solid block of stainless

\section{Radio-opaque composites}

The range of dental composites from Kent Express includes the light cured Hybrid and Micro Hybrid compositions. The resin based aesthetic restorative materials can be used in posterior and anterior restorations in Classes 1-V.

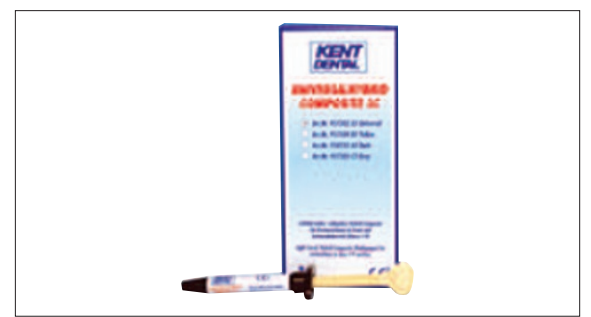

These radio-opaque composites, based on dimethacrylates with fillers, are available in four shades in $3 \mathrm{~g}$ syringes and offer reduced shrinkage, strength, condensability and polishing characteristics.

Kent Dental Flowable composite is a fluoride releasing, light activated flowable composite. Although primarily designed for use in Class V restorations, Kent Dental Flowable is also ideal for situations where access with regular composites is difficult, such as the proximal boxes of Class II restorations. This high density material is radio-opaque and over time allows the diagnosis of secondary caries.

Reader response number 56

steel and carefully bottom weighted to avoid spillages. An anti slip o-ring is also in place for extra security. With every four Pegasus Amalgam Carriers purchased at rrsp £6.50 each you will receive an Amalgam Well free of charge, a saving of £12.95. Offer ends 30 Sept 2007.

Reader response number 57 


\section{Composite with fine particles}

Spectrum TPH from Dentsply is a hybrid composite with fine particles to ensure aesthetics that look great not just immediately after placement, but for years to come.

The company has now launched the Spectrum TPH3, an improvement over Spectrum TPH. This third generation product has improved polishability due to the additional special glass fillers in the formulation.

The creamy consistency, allowing ease of shaping has been retained and it

\section{Self-etching seal}

Kuraray Dental presents a new resin cement for adhesion in several shades and for ambitious ceramic and veneer restorations. Clearfil Esthetic Cement combines the strength and long term experience of the cement Panavia, with the aesthetic spirit of the new dental age.

The product is a new composite-based cement developed for superior esthetics and adhesion. With its shade matching system, it simplifies colour selection, allowing you to easily choose a shade by developing four essential colour families, which are arranged by restorative type.

Designed with ease of use in mind, a

\section{Double strength cores}

Dentocore from Dental Sky is a core build up material with advanced fluoride release, to strengthen the surrounding tooth structure and to help prevent secondary decay. Dual cured Dentocore utilises nanofill composite technology. This ensures compressive strength for longer lasting restorations with fewer failures. The enhanced mechanical properties of Dentocore are down to the utilisation of intercalated and exfoliated nanocomposite technology.

Once cured, the likelihood of air bubbles being incorporated into the material is extremely unusual. Dentocore exhibits similar properties to dentine and as

\section{Increased torque}

The range of hi-speed air turbines from NSK features the newly developed Dual Air Jet turbine system the Ti-Max X Series. It delivers $22 \mathrm{~W}$ power, dramatically increasing torque output and offering you a high level of performance. has high fracture toughness, high wear resistance and marginal integrity. Spectrum TPH3 is available both as compule tips and syringes. To make it easier for existing customers, there is no change in the ordering codes for Spectrum TPH3. Reader response number 58

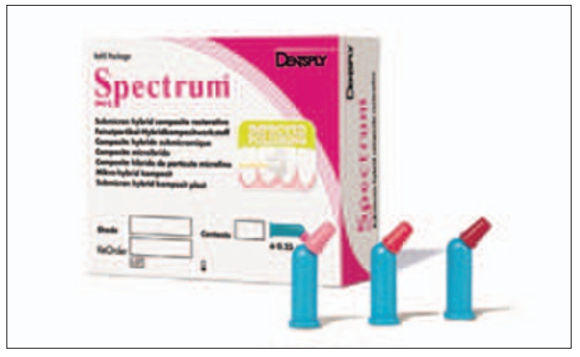

compact Automix syringe system and five realistic shades with identical try-in pastes offer adhesion with a high bond strength and a new level of colour to every type of restoration.

Reader response number 59

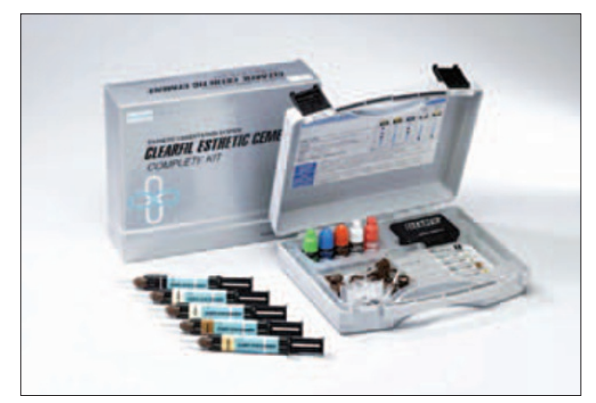

such can be prepared in the same way. When polished with fine diamond burs and flexible polishing discs a high lustre can be achieved for a great aesthetic finish. This radiopaque material is supplied in an automix syringe, cartridges or manual syringes.

Reader response number 60

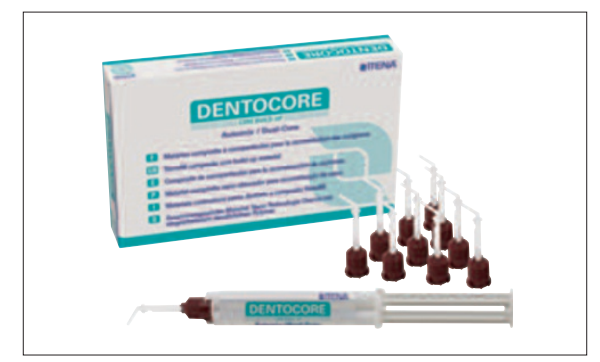

Turbine noise has been virtually eliminated with the use of advance ceramic bearings.

Reader response number 61

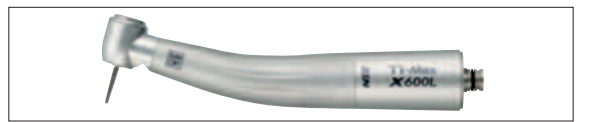

